\title{
Socio-economic characteristics, living conditions and diet quality are associated with food insecurity in France
}

\author{
Aurélie Bocquier ${ }^{1,2,3}$, Florent Vieux ${ }^{4,5}$, Sandrine Lioret ${ }^{6}$, Carine Dubuisson $^{7}$, \\ France Caillavet ${ }^{8}$ and Nicole Darmon ${ }^{4,5, *}$ \\ 'ORS PACA, Southeastern Health Regional Observatory, Marseille, France: ${ }^{2}$ INSERM, UMR912 'Economics and Social \\ Sciences Applied to Health \& Analysis of Medical Information' (SESSTIM), Marseille, France: ${ }^{3}$ Aix Marseille University, \\ UMR_S912, IRD, Marseille, France: ${ }^{4}$ INRA (Institut National de la Recherche Agronomique), UMR 1260 'Nutrition, \\ Obesity and Risk of Thrombosis', Marseille, France: ${ }^{5}$ Faculty of Medicine, Aix-Marseille Université, F-13385 Marseille, \\ France: ${ }^{6}$ Centre for Research in Epidemiology and Population Health, INSERM U1018, Villejuif, France: ${ }^{7}$ ANSES, Risk \\ Assessment Department, Dietary Survey Unit, Maisons-Alfort, France: ${ }^{8}$ INRA-ALISS, UR 1303, Ivry, France
}

Submitted 19 November 2013: Final revision received 28 October 2014: Accepted 4 November 2014: First published online 7 January 2015

\begin{abstract}
Objective: To assess the prevalence of household food insecurity (FI) in France and to describe its associations with socio-economic factors, health behaviours, diet quality and cost (estimated using mean food prices).

Design: Cross-sectional nationally representative survey. FI was assessed using an adapted version of the US Department of Agriculture's Food Insufficiency Indicator; dietary intake was assessed using a $7 \mathrm{~d}$ open-ended food record; and individual demographic, socio-economic and behavioural variables were assessed using self-administered questionnaires and interviews. Individuals experiencing FI were compared with food-secure individuals, the latter being divided into four categories according to quartiles of their income per consumption unit (FS1 to FS4). Differences among categories were analysed using $\chi^{2}$ tests, ANOVA and tests for trend.

Setting: Individual and National Dietary Survey (INCA2), 2006-2007.

Subjects: Adults aged 18-79 years ( $n$ 2624).

Results: Individuals experiencing FI represented $12 \cdot 2 \%$ of the population. They were on average younger, more frequently women and single parents with children compared with those in the other four categories. Their mean income per consumption unit was higher than that in the FS1 category, but they reported poorer material and housing conditions. The prevalence of smoking and the mean daily time spent watching television were also higher in the FI category. No significant difference among categories was found for energy intake, but mean intakes of fruits, vegetables and fish were lower, and diet quality was slightly but significantly poorer in the FI category. Daily diet cost was also lower in the FI category.

Conclusions: France is not spared by FI. FI should be routinely monitored at the national level and research should be promoted to identify effective strategies to reduce nutrition inequalities in France.
\end{abstract}

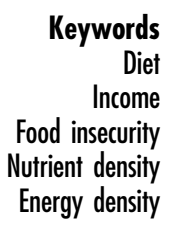

In industrialised countries there is strong evidence of a positive association between diet quality and socioeconomic status as measured by conventional indices such as occupation, education or income level ${ }^{(1-3)}$. In the 1980s and 1990s, the US authorities recognised that a subset of citizens had difficulties obtaining adequate access to food and specific quantitative indicators were developed to monitor food insecurity (FI) at the household and individual levels ${ }^{(4)}$. According to the definition of the 1989 Life Sciences Research Office expert panel, FI 'exists whenever the availability of nutritionally adequate and safe foods or the ability to acquire acceptable food in socially acceptable ways is limited or uncertain, (5). Food security implies that all people, at all times, have access to enough food for an active, healthy life 'without resorting, e.g. to emergency food supplies, scavenging, stealing and other coping strategies, ${ }^{(5,6)}$. In 1996, a broad consensus was reached on a closed definition at the World Food Summit: 'Food security exists when all people, at all times, have physical and economic access to sufficient, safe and nutritious food to meet their dietary needs and food preferences for an active and healthy life ${ }^{,(7)}$. FI appears to be a managed process, resulting first in compromises on food quality and then on food quantity ${ }^{(6,8)}$. 
Hunger, described as an 'uneasy or painful sensation caused by a lack of food, is a potential, although not necessary, consequence of food insecurity ${ }^{\text {(5). }}$.

Data from developed nations show that low income is clearly one of the most important determinants of $\mathrm{FI}^{(9-12)}$, although many food-insecure households are not in poverty $^{(9)}$. Other demographic and socio-economic factors are associated with an increased risk of FI: single-parent families, the presence of young children and housing conditions (e.g. non-home ownership) $)^{(9,10,13-15)}$. FI is a potential risk factor for suboptimal health and health behaviours among both children and adults ${ }^{(16-19)}$, including chronic diseases such as metabolic syndrome, hypertension and diabetes ${ }^{(20-22)}$, low energy intake ${ }^{(23-25)}$ poor dietary intake $^{(9,11,26,27)}$ and poor nutritional status (assessed by serum biomarkers) ${ }^{(28-30)}$.

In the USA and Canada in particular, the prevalence of FI is now regularly assessed through national surveys on diet and health based on a questionnaire that subjectively evaluates the individual's perception regarding the food situation of his or her household ${ }^{(4,31,32)}$. In European countries, only a few studies have assessed the prevalence of $\mathrm{FI}^{(33,34)}$. In France, available data are limited to specific regions ${ }^{(13)}$ or high-risk groups such as very-low-income and homeless people $^{(35)}$. In 2006-2007, indicators referring to household FI were introduced for the first time in the latest French cross-sectional nationally representative dietary survey (Étude Individuelle et Nationale des Consommations Alimentaires, INCA2, 2006-07) ${ }^{(36,37)}$. The present study aimed to (i) assess the prevalence of household FI in the French adult population and (ii) characterise individuals experiencing FI with regard to their socio-economic characteristics, living conditions, health behaviours, food consumption, diet quality and cost. For this purpose, these individuals were compared with the rest of the population and the latter was divided into four categories according to income level.

\section{Materials and methods}

\section{Study design and sample}

The French INCA2 survey methodology has been described elsewhere ${ }^{(36,37)}$. In brief, this survey was carried out between December 2005 and May 2007 by ANSES (French Agency for Food, Environmental and Occupational Health Safety; formerly the French Food Safety Agency, AFSSA) to assess dietary intake and associated behaviours in a nationally representative sample of French people. Two independent random samples of children aged between 3 and 17 years ( $n$ 1455) and adults aged between 18 and 79 years ( $n$ 2624) were obtained using a multistage cluster sampling technique previously described ${ }^{(38)}$. Only data from the adult sample were used in the present study; the participation rate (ratio of the number of individuals ultimately included in the study to the number of households whose composition was known) was $63 \%{ }^{(39)}$.
The survey included two home visits by trained investigators. Dietary intake was assessed using a $7 \mathrm{~d}$ food record. Socio-economic, demographic and behavioural variables were collected at the individual level using a self-administered questionnaire and an interview. During the first visit, the investigator spent 45-60 min explaining the survey and food record. After $7 \mathrm{~d}$, the investigator returned to review both documents (e.g. to check for often forgotten foods such as bread or water in the food record and whether there were any questions missed in the self-administered questionnaire). The investigator then conducted an interview regarding socio-economic status and lifestyle.

The INCA2 survey was approved by the French National Commission for Computed Data and Individual Freedom (Commission Nationale de l'Informatique et des Libertés, CNIL).

\section{Food insecurity}

The INCA2 survey included the US Department of Agriculture's Food Sufficiency Indicator using a four-part response $^{(4)}$. The question on food insufficiency, defined as an inadequate amount of food intake due to a lack of money or resources, ${ }^{, 40)}$, was used in previous American surveys $^{(24,41,42)}$. It has been shown to be a valuable proxy of food insecurity ${ }^{(4)}$. Respondents were asked which of the following statements best described the food currently consumed in their household: (i) 'Enough of the kinds of food we want to eat'; (ii) 'Enough, but not always the kinds of food we want to eat'; (iii) 'Sometimes not enough to eat'; or (iv) 'Often not enough to eat'. Respondents who reported one of the three latter responses were asked additional questions about the reasons for their response (e.g. on a diet to lose weight, or lack of time, not enough money, lack of self-cooking facilities) ${ }^{(43)}$. Individuals having reported getting enough but not always the kinds of food they want to eat, or sometimes or often not getting enough to eat because of lack of money were classified as living in a household experiencing FI for financial reasons (hereafter FI). The remaining individuals were considered as living in households experiencing food security (FS) and were divided into four categories according to quartile of the household income per consumption unit (see below): FS1 (FS individuals in the lowest quartile of income per consumption unit) to FS4 (FS individuals in the highest quartile).

\section{Demographic and socio-economic variables}

The following variables were available for each participant: gender, age and household type, the latter being defined according to both the marital status and the number of children (single without child, single with at least one child, other). The socio-occupational status of the head of the household was divided into 'high', 'intermediate' and 'low'. 'High' was assigned to executive, top-management and professional classes; 'intermediate' to middle professions 
(office employees, technicians and similar); and 'low' to manual workers and unemployed people. A fourth class, labelled as 'economically inactive', included retired people, students and housewives/house husbands who had identified themselves as the head of the household ${ }^{(36)}$. The level of education of the head of the household was divided into 'high', 'intermediate' and 'low'. 'High' was assigned to university education, 'intermediate' to high school and 'low' to mid-secondary or below ${ }^{(44)}$. Income per consumption unit was calculated as self-reported household total net income divided by the number of consumption units in the household. The number of consumption units was calculated using the modified equivalent scale ( 1.0 consumption unit for the householder, $0 \cdot 5$ for other household members aged 14 or over, and 0.3 for each child aged less than 14 years old) of the Organisation for Economic Co-operation and Development ${ }^{(45)}$. Finally, the individual perceived financial difficulties of the household (living comfortably, getting by, finding it difficult, impossible without debt) were assessed $^{(46)}$ based on whether at least one of the household members sometimes had to forego health care for financial reasons (yes, no).

\section{Living conditions}

Living conditions were assessed using data on housing and other material conditions: housing tenure (owner, home ownership, tenant, other), having a garden (yes, no) and car ownership (yes, no). A variable indicating self-cooking facilities was defined according to the presence of a refrigerator, a freezer, an oven or a microwave in the house. Individuals with fewer than three of these four electrical devices were categorised as having low selfcooking facilities.

\section{Health behaviours}

In the self-administered questionnaire, the respondents reported their usual snack eating frequency. 'Snacks' were defined as eating episodes in addition to breakfast and main meals (i.e. lunch and dinner). Those answering 'two or three times a day' or 'four times a day' were combined into one group termed 'eat at least two times a day between meals'. During the interview, participants reported the time spent watching television during the past week for days of work and days off separately. Then, the mean time spent watching television during the past week in $\mathrm{min} / \mathrm{d}$ weighted by the number of days of work and days off was calculated. The current smoking status (occasional or daily smoker, non-smoker) was also assessed using the self-administered questionnaire.

\section{Food consumption, diet quality and diet cost}

In the $7 \mathrm{~d}$ open-ended food record, participants reported each food or drink consumed for each type of eating occasion, i.e. meals and snacks. One line of the record corresponded to one item consumed (food or drink). Participants estimated portion sizes either using the SU.VI.MAX (SUpplémentation en VItamines et en Minéraux AntioXydants) validated photographic booklet $^{(47)}$ or by expressing portion sizes by weight or household measures (spoon). Average daily nutritional intakes were evaluated using the French food composition databases from $2006^{(48)}$.

Diet quality was assessed using three indicators: the mean adequacy ratio (MAR), the mean excess ratio (MER) and the dietary energy density $(\mathrm{ED})^{(49)}$. The MAR was used as an indicator of good nutritional quality and was calculated for the diet of each individual as the mean percentage of the daily recommended intakes for twenty key nutrients (protein, fibre, retinol equivalents, thiamin, riboflavin, niacin, vitamin $\mathrm{B}_{6}$, folate, vitamin $\mathrm{B}_{12}$, ascorbic acid, vitamin $\mathrm{E}$, vitamin $\mathrm{D}, \mathrm{Ca}, \mathrm{K}, \mathrm{Fe}, \mathrm{Mg}, \mathrm{Zn}, \mathrm{Cu}$, iodine and Se); each percentage was truncated at 100 so that a high intake of one nutrient could not compensate for the low intake of another ${ }^{(49)}$. The MER was used as an indicator of poor nutritional quality and was calculated for each diet as the mean percentage excess relative to the maximum recommended values for three nutrients (SFA, Na and free sugars); 100 was subtracted from each percentage except for percentages <100, which were set to 0 so that a low intake of one of these nutrients could not compensate for the high intake of another ${ }^{(49)}$. Dietary ED (in $\mathrm{kcal} / 100 \mathrm{~g}$ diet) is inversely related to overall nutritional quality ${ }^{(50,51)}$ and was calculated by dividing energy intake by diet weight. Only items typically consumed as foods, including soups, were included in the calculation of ED, whereas foods typically consumed as beverages such as milk, juices and other drinks were excluded $^{(49)}$.

Finally, dietary costs $(€ / d)$ were estimated using mean food prices obtained from the 2006 Kantar Worldpanel purchase database, which gives the annual expenditure and the quantity purchased for each food item available on the market in a representative sample of more than 15000 French households in $2006^{(52)}$. The mean prices were estimated by dividing the annual expenditures by the quantities purchased. Daily diet cost was then calculated for each individual by multiplying the quantity of each food consumed by its mean price.

\section{Statistical analysis}

INCA2 survey data were weighted for unequal sampling probabilities and for differential non-responses by region, agglomeration size, age, sex, occupation of the household head, size of the household and season. Among the 2624 adult participants, $20.4 \%$ did not report their household income (missing data); these individuals were less likely to have a 'low' socio-occupational status and were more likely to live comfortably and be the home owner (results not shown). To estimate their income, these individuals with missing information were matched to individuals with complete income data according to their sociodemographic characteristics (age, sex, socio-occupational status, level of education, marital status) and level of living 
variables (home owner or not, home equipment) using the Kohonen algorithm ${ }^{(53)}$.

First, the prevalence of FI in the whole adult sample and the demographic, socio-economic characteristics and health behaviours were described for each of the five categories of individuals (FI, FS1 to FS4).

Then, (non-alcoholic) energy intake $(\mathrm{kcal} / \mathrm{d})$ and average food intake $(\mathrm{g} / \mathrm{d})$ of eleven food groups and twentytwo subgroups, as well as the means and $95 \%$ confidence intervals of the MAR (\%), MER (\%), ED (kcal/100 g) and cost $(€ / d)$, were calculated for each of the five categories of individuals. For the purpose of these analyses, 706 (26.9\%) under-reporters were excluded, as defined by comparing the reported energy intake to the BMR as estimated from the Schofield equations ${ }^{(54)}$ and a cut-off value for physical activity level as defined by Black $^{(55)}$. When specified, adjustments were made for age, gender and energy intake (except energy intake, which was adjusted for age and gender only).

Differences among the categories of individuals were analysed using the $\chi^{2}$ test for categorical variables and ANOVA for continuous variables. Linear trends were tested with Cochran-Armitage tests for $\chi^{2}$ tests and analysis of contrasts for ANOVA. Post hoc tests were performed to compare the FI category with the FS1 category. All analyses were based on two-tailed $P$ values at an $\alpha$ risk level of $5 \%$ for statistical significance (i.e. $P<0.05$ ). They were computed using the SAS statistical software package version 9.2 and the SURVEYREG, SURVEYMEANS, URVEYFREQ and GLM procedures.

\section{Results}

\section{Prevalence of food insecurity}

Answers from the 2624 INCA2 adult participants to the FI question are summarised in Table 1 . Together, $12.2 \%$ were considered as living in a household experiencing FI for financial reasons.

\section{Socio-economic and behavioural characteristics and living conditions}

Participants were aged 45.4 (SD 16.5) years on average and $51.4 \%$ were women. The mean income per consumption unit was $1272 €$ (SD 818) per month (Table 2).
All socio-economic and behavioural characteristics and living conditions differed significantly among the five categories of individuals (Table 2 and Fig. 1). In particular, individuals experiencing FI were, compared with others (i.e. individuals in the FS category; mean and frequency and $P$ values not shown), significantly younger, more frequently women, single with at least one child and more frequently had a 'low' socio-occupational status. When individuals experiencing FI were compared with those in the FS1 category ( $P$ values for post hoc tests not shown), their mean income per consumption unit was significantly higher but they more frequently reported the following statements or situations: a financial situation that was 'difficult or impossible without debt', foregoing health care for financial reasons and having no garden; they were also less frequently owners of their accommodation.

A significant association was observed between the household food insecurity/income level variable and the percentage of occasional or daily smokers and of individuals eating at least two times per day between meals, as well as the average time spent watching television daily. For all these associations, a significant decreasing trend was found from FI to FS4, with the highest value observed for FI.

\section{Food group and subgroup consumption, diet quality and diet cost}

Energy intake differed significantly among the five categories in a U-shaped manner ( $P$ 0.038), but absolute differences were slight (Table 3 ). The total consumption of fruit and vegetables increased linearly from FI to FS4 (338.7 to $455.3 \mathrm{~g} / \mathrm{d}, P<0.001, P$ trend $<0.001$ ), due to the increase in vegetables, fresh fruit, and processed fruit and juices. Overall, the mean consumption of 'sweet foods and drinks' decreased from $208.2 \mathrm{~g} / \mathrm{d}$ in FI to $159.3 \mathrm{~g} / \mathrm{d}$ in FS4 $(P=0.002, P$ trend $<0.001)$, mainly due to a higher consumption of soft drinks in the FI and FS1 categories than in the other groups ( $P$ values for post hoc tests not shown). Consumption of starchy foods was the highest in the FS1 category and an intermediate consumption level was observed for the FI category. No significant differences were found among the five categories for 'dairy products', 'mixed dishes and salted snacks' and the 'added fats' food groups. No significant differences were found either for the 'meat, poultry, fish, eggs' food group, but within that group, the

Table 1 Prevalence of household food insecurity among the adult participants ( $n$ 2624), Étude Individuelle et Nationale des Consommations Alimentaires (INCA2), France, 2006-2007

\begin{tabular}{lccr}
\hline & $n$ & Weighted \% & $95 \% \mathrm{Cl}$ \\
\hline Enough of the kinds of food we want to eat & 2133 & 83.1 & $81.2,85.0$ \\
Enough, but not always the kinds of food we want to eat & 457 & 16.0 & $14.2,17.8$ \\
Sometimes not enough to eat & 27 & 0.78 & $0.36,1.20$ \\
Often not enough to eat & 7 & 0.13 & $0.03,0.23$ \\
Food insecurity for financial reasons & 365 & 12.2 & $10.6,13.8$ \\
\hline
\end{tabular}

*Enough but not always the kinds of food we want to eat, or sometimes or often not enough to eat for financial reasons. 
Table 2 Demographic, socio-economic characteristics and health behaviours of the adult participants $(n$ 2624) living in either food-insecure (FI) households or food-secure households (FS1 to FS4), Étude Individuelle et Nationale des Consommations Alimentaires (INCA2), France, 2006-2007

\begin{tabular}{|c|c|c|c|c|c|c|c|c|}
\hline & $\mathrm{FI}$ & FS1 & FS2 & FS3 & FS4 & Total & $P^{*}$ & $P$ trend $^{*}$ \\
\hline \multicolumn{9}{|l|}{ Age (years) ( $n$ 2624) } \\
\hline Mean & $42 \cdot 3$ & 43.8 & 47.4 & 44.9 & $47 \cdot 3$ & $45 \cdot 4$ & $<0.001$ & 0.001 \\
\hline SD & $14 \cdot 2$ & $17 \cdot 1$ & 17.4 & $16 \cdot 9$ & $15 \cdot 7$ & $16 \cdot 5$ & & \\
\hline Participant gender - women ( $n$ 2624) & $60 \cdot 2$ & 59.2 & 47.6 & $49 \cdot 3$ & $45 \cdot 1$ & 51.4 & $<0.001$ & $<0.001$ \\
\hline Household type ( $n$ 2624) & & & & & & & $<0.001$ & \\
\hline Single without child & $19 \cdot 1$ & $10 \cdot 3$ & 9.5 & 24.4 & $9 \cdot 0$ & $14 \cdot 2$ & & 0.196 \\
\hline Single with at least one child & 4.4 & $4 \cdot 0$ & $2 \cdot 3$ & 1.7 & $1 \cdot 1$ & 2.5 & & $<0.001$ \\
\hline Other & $76 \cdot 5$ & $85 \cdot 6$ & $88 \cdot 2$ & 73.9 & 89.9 & 83.2 & & $<0.001$ \\
\hline Professional category of the $\mathrm{HH}(n$ 2622) & & & & & & & $<0.001$ & \\
\hline Low & $39 \cdot 6$ & $30 \cdot 1$ & $25 \cdot 9$ & $21 \cdot 2$ & $9 \cdot 0$ & 23.5 & & $<0.001$ \\
\hline Medium & $27 \cdot 7$ & 29.9 & $30 \cdot 2$ & 35.7 & 31.8 & 31.5 & & 0.167 \\
\hline High & 3.9 & $3 \cdot 1$ & $6 \cdot 3$ & $12 \cdot 3$ & $30 \cdot 0$ & $12 \cdot 1$ & & $<0.001$ \\
\hline Economically inactive & $28 \cdot 8$ & $36 \cdot 9$ & $37 \cdot 7$ & $30 \cdot 8$ & $29 \cdot 2$ & $32 \cdot 9$ & & 0.018 \\
\hline Education level of the $\mathrm{HH}(n 2573)$ & & & & & & & & $<0.001$ \\
\hline Low & 23.4 & $30 \cdot 7$ & $22 \cdot 3$ & $17 \cdot 2$ & $7 \cdot 7$ & $19 \cdot 7$ & & $<0.001$ \\
\hline Medium & $60 \cdot 0$ & 55.7 & $59 \cdot 0$ & $51 \cdot \overline{3}$ & 41.5 & $52 \cdot 6$ & & $<0.001$ \\
\hline High & $16 \cdot 5$ & $13 \cdot 5$ & 18.6 & 31.5 & $50 \cdot 8$ & $27 \cdot 7$ & & $<0.001$ \\
\hline \multicolumn{9}{|l|}{ Income per consumption unit ( $€$ /month) ( $n$ 2624) } \\
\hline Mean & 840 & 471 & 906 & 1378 & 2457 & 1272 & $<0.001$ & $<0.001$ \\
\hline SD & 508 & 177 & 127 & 175 & 694 & 818 & & \\
\hline Perception of household financial situation ( $n$ 2615) & & & & & & & $<0.001$ & \\
\hline Living comfortably & $10 \cdot 0$ & 43.8 & 53.7 & $68 \cdot 2$ & $85 \cdot 2$ & $56 \cdot 9$ & & $<0.001$ \\
\hline Getting by & 58.8 & 48.7 & 44.2 & $30 . \overline{4}$ & 13.4 & $36 \cdot 7$ & & $<0.001$ \\
\hline Finding it difficult & $26 \cdot 2$ & $7 \cdot 3$ & 1.9 & 1.0 & 1.2 & $5 \cdot 6$ & & $<0.001$ \\
\hline Impossible without debt & $5 \cdot 0$ & 0.1 & 0.2 & 0.4 & 0.1 & 0.8 & & $<0.001$ \\
\hline Forego health care for financial reasons ( $n$ 2622) & $32 \cdot 6$ & $9 \cdot 7$ & $5 \cdot 8$ & $6 \cdot 3$ & $2 \cdot 3$ & $9 \cdot 2$ & $<0.001$ & $<0.001$ \\
\hline Eat at least two times a day between meals $†(n$ 2514) & $24 \cdot 9$ & $20 \cdot 4$ & 14.5 & $15 \cdot 6$ & $13 \cdot 4$ & $17 \cdot 0$ & $<0.001$ & 0.001 \\
\hline \multicolumn{9}{|l|}{ Time spent watching television $(\mathrm{min} / \mathrm{d})(n 2615)$} \\
\hline Mean & $179 \cdot 8$ & $157 \cdot 3$ & $154 \cdot 8$ & $145 \cdot 6$ & $128 \cdot 3$ & $150 \cdot 1$ & $<0.001$ & $<0.001$ \\
\hline SD & $113 \cdot 9$ & $110 \cdot 9$ & 104.7 & $106 \cdot 1$ & 88.5 & $105 \cdot 3$ & & \\
\hline Occasional or daily smoker ( $n$ 2569) & $47 \cdot 7$ & 31.2 & $26 \cdot 8$ & $30 \cdot 7$ & $27 \cdot 1$ & 31.2 & $<0.001$ & $<0.001$ \\
\hline
\end{tabular}

$\mathrm{HH}$, head of the household

Data presented are percentages unless otherwise indicated.

${ }^{*}$ Statistical significance of the differences among the five categories of individuals (FI, FS1 to FS4): $x^{2}$ tests for categorical variables and ANOVA for continuous variables; and test for linear trend (Cochran-Armitage tests for $x^{2}$ tests and analysis of contrasts for ANOVA) when significant differences were found among the five categories. †Self-reported usual snack (i.e. other eating episodes apart from breakfast and main meals) eating frequency: 'two or three times a day' or 'four times a day'.

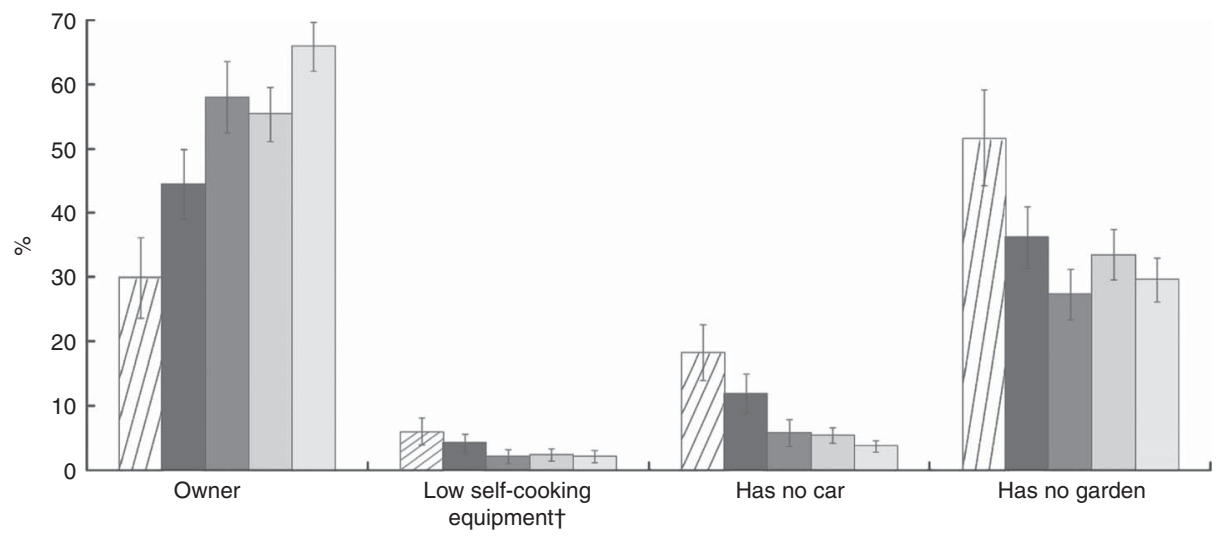

Fig. 1 Living conditions of adult participants living in either food-insecure (FI) households ( $\square$ ) or food-secure households (FS1, $\square$; FS2, $\square$; FS3, $\square$; FS4, $\square)^{*}$, Étude Individuelle et Nationale des Consommations Alimentaires (INCA2), France, 2006-2007. Values are percentages with their $95 \%$ confidence intervals represented by vertical bars. ${ }^{\star}$ Ownership: $n 2619$; self-cooking equipment: $n 2623$; car: $n$ 2620; garden: $n$ 2623. Statistical significance of the differences among the five categories of individuals $\left(x^{2}\right.$ tests): $P<0.001$. + Low self-cooking equipment: fewer than three of the four following electrical devices in the house: refrigerator, freezer, oven or microwave

mean consumption of fish increased from $23.4 \mathrm{~g} / \mathrm{d}$ in FI to $33.6 \mathrm{~g} / \mathrm{d}$ in FS4 $(P<0 \cdot 001, P$ trend $<0 \cdot 001)$. Finally, the mean consumption of alcoholic beverages increased from the FI and FS1 categories (137.9 and $127.5 \mathrm{~g} / \mathrm{d}$, respectively) to the FS4 category $(183.0 \mathrm{~g} / \mathrm{d} ; P$ trend $=0.003$; Table 3 ).
Results showed a poorer diet quality among individuals experiencing FI (Fig. 2): the mean MAR increased ( $P$ trend $<0.001)$ and the MER and ED decreased ( $P$ trend 0.001 and $0 \cdot 002$, respectively) from FI to FS4. Dietary costs increased from $6 \cdot 3 € / d$ in FI to $7 \cdot 1 € / d$ in FS4 ( $P$ trend $<0 \cdot 001$; Fig. 2 ). 
Table 3 Mean energy intake $(\mathrm{kJ} / \mathrm{d}$; $\mathrm{kcal} / \mathrm{d})$ and consumption of food groups and food subgroups $(\mathrm{g} / \mathrm{d})^{\star}$ by adult participants $(n 1918+)$ living in either food-insecure (FI) households or food-secure households (FS1 to FS4), Étude Individuelle et Nationale des Consommations Alimentaires (INCA2), France, 2006-2007

\begin{tabular}{|c|c|c|c|c|c|c|c|c|c|c|c|c|}
\hline & \multicolumn{2}{|c|}{$\mathrm{FI}(n$ 239) } & \multicolumn{2}{|c|}{ FS1 ( $n$ 368) } & \multicolumn{2}{|c|}{ FS2 ( $n$ 379) } & \multicolumn{2}{|c|}{ FS3 ( $n$ 475) } & \multicolumn{2}{|c|}{ FS4 ( $n$ 457) } & \multirow[b]{2}{*}{$P \ddagger$} & \multirow[b]{2}{*}{$P$ trend $\ddagger$} \\
\hline & Mean & SD & Mean & SD & Mean & SD & Mean & SD & Mean & SD & & \\
\hline Energy intake (non-alcoholic) $(\mathrm{kJ} / \mathrm{d})$ & 9164 & 146 & 9084 & 105 & 8840 & 107 & 9350 & 98 & 9089 & 99 & 0.038 & 0.833 \\
\hline Energy intake (non-alcoholic) (kcal/d) & $2190 \cdot 2$ & 34.9 & $2171 \cdot 1$ & $25 \cdot 2$ & $2112 \cdot 9$ & $25 \cdot 6$ & 2234.7 & 23.4 & $2172 \cdot 3$ & $23 \cdot 6$ & 0.038 & 0.833 \\
\hline Fruit and vegetables & 338.7 & $15 \cdot 2$ & $405 \cdot 0$ & $11 \cdot 0$ & 429.6 & 11.1 & 439.8 & $10 \cdot 2$ & $455 \cdot 3$ & $10 \cdot 3$ & $<0.001$ & $<0.001$ \\
\hline Vegetables & $121 \cdot 7$ & $5 \cdot 6$ & $126 \cdot 6$ & $4 \cdot 1$ & 143.8 & $4 \cdot 1$ & 139.6 & 3.8 & $147 \cdot 3$ & 3.8 & $<0.001$ & $<0.001$ \\
\hline Fresh fruit & $117 \cdot 0$ & 9.1 & $127 \cdot 0$ & 6.6 & $134 \cdot 0$ & 6.6 & $145 \cdot 1$ & $6 \cdot 1$ & $166 \cdot 1$ & $6 \cdot 1$ & 0.003 & $<0.001$ \\
\hline Processed fruit or juice & $38 \cdot 3$ & $6 \cdot 5$ & $72 \cdot 6$ & 4.7 & 69.9 & 4.8 & 81.5 & 4.4 & $72 \cdot 7$ & 4.4 & $<0.001$ & $<0.001$ \\
\hline Dried fruit & 1.9 & 0.4 & 1.9 & 0.3 & 1.8 & 0.3 & 1.8 & 0.3 & $2 \cdot 3$ & 0.3 & 0.602 & \\
\hline Soup & $59 \cdot 8$ & 7.6 & $76 \cdot 9$ & 5.5 & $80 \cdot 2$ & $5 \cdot 6$ & 71.8 & $5 \cdot 1$ & 66.9 & $5 \cdot 2$ & 0.094 & \\
\hline Starchy foods & $247 \cdot 3$ & 6.6 & 273.7 & 4.8 & 254.1 & 4.8 & $236 \cdot 7$ & 4.4 & $227 \cdot 3$ & $0 . \overline{5}$ & $<0.001$ & $<0.001$ \\
\hline Refined grains & $167 \cdot 1$ & 5.5 & 181.4 & 4.0 & 171.9 & $4 \cdot 1$ & 152.5 & 3.7 & $152 \cdot 1$ & 3.8 & $<0.001$ & $<0.001$ \\
\hline Unrefined starches§ & $76 \cdot 3$ & 3.9 & 87.2 & 2.8 & 78.8 & 2.9 & 78.0 & $2 \cdot 6$ & $70 \cdot 3$ & $2 \cdot 7$ & 0.010 & 0.046 \\
\hline Breakfast cereals & 3.9 & 1.1 & $5 \cdot 1$ & 0.8 & 3.5 & 0.8 & $6 \cdot 2$ & 0.8 & 4.9 & 0.8 & 0.214 & \\
\hline Dairy products & $179 \cdot 6$ & 11.4 & $181 \cdot 0$ & 8.3 & $194 \cdot 1$ & 8.4 & $216 \cdot 6$ & $7 \cdot 7$ & 193.5 & $7 \cdot 8$ & 0.160 & \\
\hline Milk and fresh dairy products & $146 \cdot 7$ & 11.5 & 148.4 & 8.3 & 163.0 & 8.4 & $184 \cdot 3$ & $7 \cdot 7$ & $159 \cdot 1$ & $7 \cdot 8$ & 0.149 & \\
\hline Cheese & $32 \cdot 8$ & 1.8 & $32 \cdot 6$ & 1.3 & $31 \cdot 1$ & 1.3 & $32 \cdot 3$ & $1 \cdot 2$ & 34.3 & 1.2 & 0.639 & \\
\hline Meat, poultry, fish, eggs & $154 \cdot 3$ & 4.2 & $166 \cdot 7$ & 3.1 & $165 \cdot 7$ & 3.1 & $160 \cdot 6$ & 2.9 & 158.0 & 2.9 & 0.192 & \\
\hline Meat and poultry & 114.7 & 3.9 & 123.4 & 2.8 & 121.5 & 2.8 & $113 \cdot 2$ & $2 \cdot 6$ & 111.6 & $2 \cdot 6$ & 0.067 & \\
\hline Fish & 23.4 & $2 \cdot 0$ & $27 \cdot 9$ & 1.4 & $28 \cdot 1$ & 1.4 & $31 \cdot 1$ & $1 \cdot 3$ & 33.6 & 1.3 & $<0.001$ & $<0.001$ \\
\hline Eggs & $16 \cdot 1$ & 1.2 & $15 \cdot 4$ & 0.9 & $16 \cdot 1$ & 0.9 & $16 \cdot 3$ & 0.8 & 12.9 & 0.8 & 0.036 & 0.110 \\
\hline Mixed dishes and salted snacks\| & $126 \cdot 7$ & $6 \cdot 1$ & $123 \cdot 5$ & 4.4 & $119 \cdot 3$ & 4.5 & $121 \cdot 7$ & $4 \cdot 1$ & $116 \cdot 6$ & $4 \cdot 1$ & 0.753 & \\
\hline Mixed dishes & $68 \cdot 1$ & 4.9 & 73.9 & 3.6 & 74.6 & 3.6 & 69.5 & $3 \cdot 3$ & 63.9 & 3.3 & 0.371 & \\
\hline Salted snacks & 58.6 & 3.5 & $49 \cdot 6$ & $2 \cdot 5$ & 44.8 & 2.6 & $52 \cdot 2$ & 2.4 & $52 \cdot 7$ & 2.4 & 0.046 & 0.432 \\
\hline Sweet foods and drinks & $208 \cdot 2$ & $12 \cdot 2$ & $204 \cdot 3$ & 8.8 & $166 \cdot 0$ & $9 \cdot 0$ & 171.6 & $8 \cdot 2$ & $159 \cdot 3$ & $8 \cdot 3$ & 0.002 & $<0.001$ \\
\hline Soft drinks & $90 \cdot 3$ & $11 \cdot 2$ & $102 \cdot 0$ & 8.1 & 51.5 & 8.2 & 53.8 & $7 \cdot 6$ & 45.9 & $7 \cdot 6$ & $<0.001$ & $<0.001$ \\
\hline Desserts & $64 \cdot 1$ & 3.9 & $56 \cdot 6$ & $2 \cdot 8$ & $65 \cdot 6$ & $2 \cdot 8$ & $69 \cdot 8$ & 2.6 & $62 \cdot 9$ & 2.6 & 0.054 & \\
\hline Sweets & $36 \cdot 2$ & $2 \cdot 1$ & 31.0 & 1.5 & 29.4 & 1.5 & 30.8 & 1.4 & 35.5 & 1.4 & 0.005 & 0.801 \\
\hline Pastries & 17.5 & 1.7 & 14.7 & 1.3 & $19 \cdot 6$ & 1.3 & $17 \cdot 2$ & 1.2 & $15 \cdot 0$ & 1.2 & 0.207 & \\
\hline Added fats & $46 \cdot 0$ & 1.5 & $45 \cdot 0$ & $1 \cdot 1$ & 44.9 & $1 \cdot 1$ & $44 \cdot 3$ & 1.0 & 44.7 & 1.0 & 0.979 & \\
\hline Vegetable fats & $22 \cdot 7$ & 1.1 & 23.2 & 0.8 & $22 \cdot 7$ & 0.8 & $22 \cdot 9$ & 0.7 & $22 \cdot 8$ & 0.7 & 0.995 & \\
\hline Animal fats & $14 \cdot 6$ & 0.9 & 13.0 & 0.7 & 14.0 & 0.7 & $13 \cdot 3$ & 0.6 & 13.4 & 0.6 & 0.764 & \\
\hline Sauces, spices & 8.8 & 0.8 & 8.9 & 0.6 & 8.2 & 0.6 & $8 \cdot 1$ & 0.5 & 8.5 & 0.5 & 0.944 & \\
\hline Water & 739.8 & 39.7 & 743.4 & $28 \cdot 8$ & $796 \cdot 3$ & 29.2 & 808.5 & $26 \cdot 7$ & 789.8 & $26 \cdot 9$ & 0.416 & \\
\hline 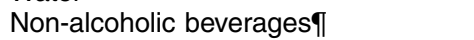 & 452.7 & $23 \cdot 1$ & $367 \cdot 0$ & $16 \cdot 7$ & 354.4 & $17 \cdot 0$ & 377.4 & $15 \cdot 6$ & $427 \cdot 1$ & $15 \cdot 7$ & $<0.001$ & 0.659 \\
\hline Alcoholic beverages & 137.9 & $13 \cdot 2$ & $127 \cdot 5$ & $9 \cdot 6$ & $149 \cdot 1$ & 9.7 & 161.0 & 8.9 & 183.0 & $9 \cdot 0$ & 0.035 & 0.003 \\
\hline Other ${ }^{\star \star}$ & 10.5 & 3.2 & 8.2 & $2 \cdot 3$ & $9 \cdot 0$ & $2 \cdot 4$ & $7 \cdot 1$ & $2 \cdot 2$ & 13.5 & $2 \cdot 2$ & 0.481 & 0.608 \\
\hline
\end{tabular}

*Means are adjusted for age, gender and energy intake (except means of energy intake, adjusted for age and gender only).

†Under-reporters for energy intakes were excluded from these analyses.

¥Statistical significance of the differences among the five categories of individuals (FI, FS1 to FS4) using ANOVA; and test for linear trend (analysis of contrasts) when significant differences were found among the five categories.

§lncludes unrefined grains, legumes and potatoes.

IIMixed dishes include home-made dishes, out-of-home consumption and ready-made dishes purchased in stores.

Tlnclude light soft drinks and hot drinks but not sugary drinks.

${ }^{\star \star}$ For example meal replacements, aspartame sweetener, brewer's yeast, tofu, shortcrust baked pastry, flaky cooked pastry.

\section{Discussion}

Based on a representative national sample of adults, the prevalence of household FI in France was estimated to be $12 \cdot 2 \%$ in 2006-2007. This finding is in between the values observed in the USA between 2005 and 2007 (11\%) and in $2008(14.5 \%)^{(56)}$, and is higher than that observed in both Canada in 2007-2008 $(7 \cdot 7 \%)^{(57)}$ and the Paris metropolitan area, which is the wealthiest region in France, in 2010 $(6 \cdot 3 \%)^{(13,58)}$. Beyond methodological differences between studies (in particular regarding FI assessment), variation in FI prevalence between countries may be due to differences in the state of national economies, socio-economic characteristics of the population (e.g. income distribution), tax/ tax-credit arrangements and the provision of in-kind benefits (e.g. food assistance, health care, housing assistance) ${ }^{(59)}$.
Consistent with previous studies carried out in the USA, Canada, England, Finland and one French region $^{(9,13,31,33,34,43)}$, the present study showed that individuals reporting household FI were younger, more frequently women, single parents with children, non-home owners and had lower income than those living in foodsecure households. The greater vulnerability of women could result from the dynamic nature of experiencing FI within the household: parents, particularly women, tend to deprive themselves to protect their children against hunger ${ }^{(6)}$. The gender effect could however be confounded by family composition because women are heavily overrepresented among single-parent families ${ }^{(60)}$, as previously observed $^{(13)}$. It is noteworthy that there is a higher risk of FI among single-parent families despite the existence of a supplemental familial allowance for single-parent families 
(a)

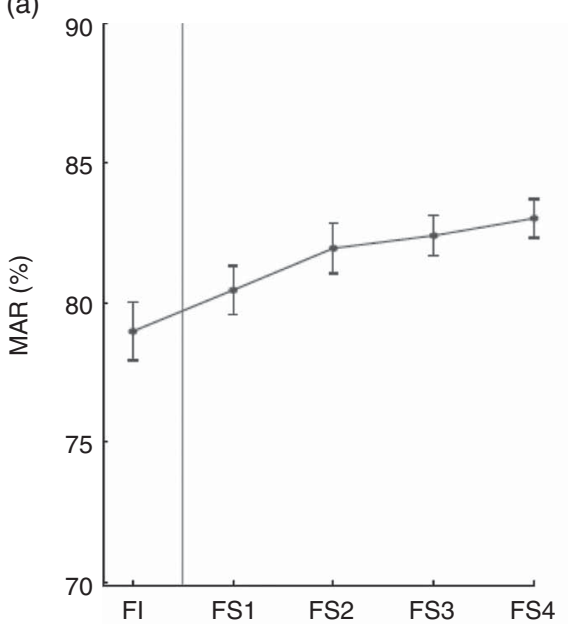

(c)

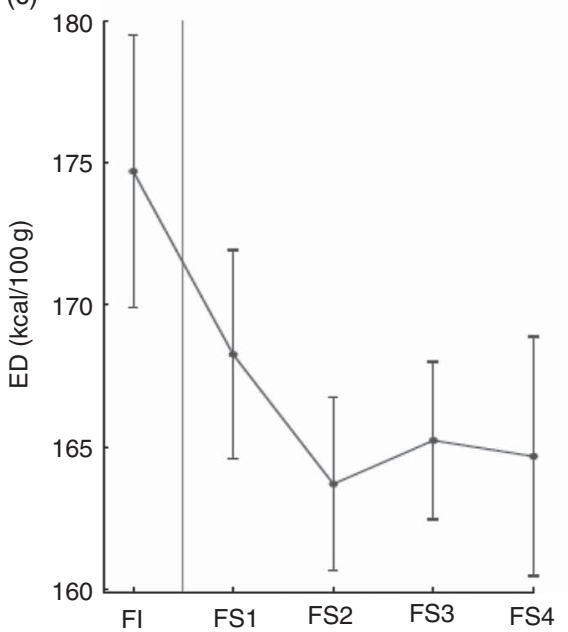

(b)

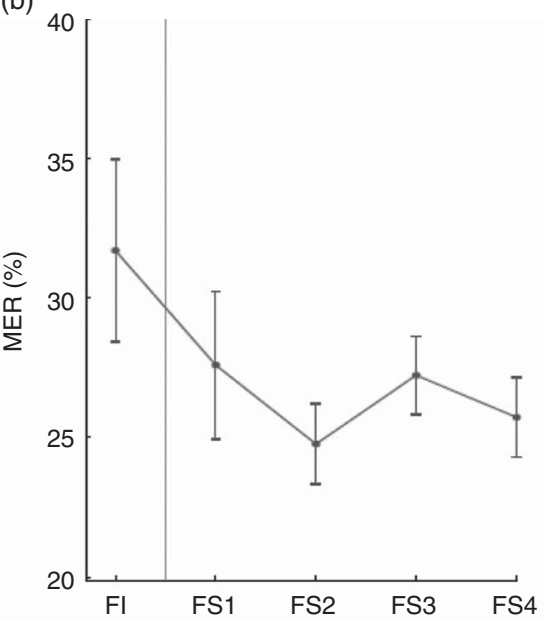

(d)

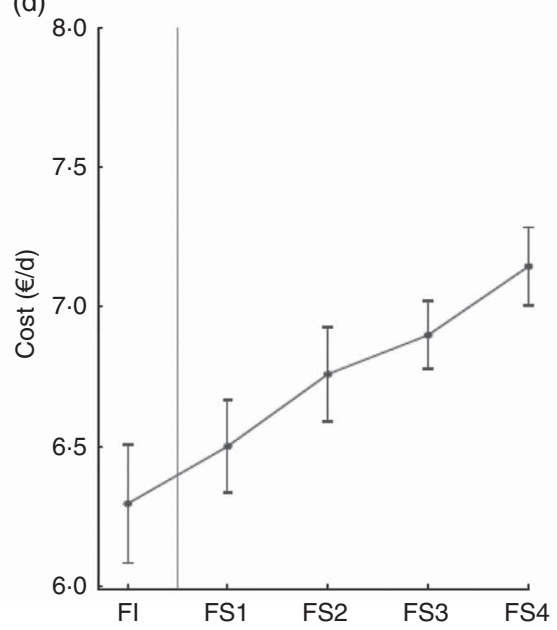

Fig. 2 (a) Mean adequacy ratio (MAR), (b) mean excess ratio (MER), (c) energy density (ED)* and (d) cost of the diet of adult participants $(n 1918 \dagger$ ) living in either food-insecure (FI) households or food-secure households (FS1 to FS4), Étude Individuelle et Nationale des Consommations Alimentaires (INCA2), France, 2006-2007. Values are means, adjusted for age, gender and energy intake, with their $95 \%$ confidence intervals represented by vertical bars. *Only items typically consumed as foods, including soups, were included in calculation of ED; $1 \mathrm{kcal}=4.184 \mathrm{~kJ}$. †Under-reporters of energy intake were excluded from these analyses

with low income in France. This is of particular concern given that FI has been associated with several social, emotional and health consequences among children ${ }^{(6,12,61)}$.

The relationship between income and FI has been well established ${ }^{(9,13,33,34)}$. However, the present study, based on comparisons between individuals experiencing household FI and those living in food-secure households divided into four categories according to income level (FS1 to FS4), suggests a somewhat more nuanced situation. Mean income level in the FI category ( $840 € /$ month) was just above the French poverty level (defined as $50 \%$ of the median French income: $804 € /$ month in 2008) and nearly twice as high as in the FS1 category (food-secure households with a very low income: $471 € /$ month). Yet, using both subjective and objective indicators, worse living conditions were found in the FI category than in the FS1 (e.g. perceived financial difficulties, foregone medical care and fewer domestic electrical devices). This suggests that individuals experiencing household FI have to address significant expenditures (e.g. housing rent, heating costs and child-care expenses) that affect living conditions and cut back the available budget for food. The estimated diet cost was the lowest in the FI category ( $6 \cdot 3 €$ /person per $\mathrm{d}$ ) in the present study. Interestingly, and consistent with the literature $^{(62)}$, the present study also suggests that these individuals may have greater expenditures due to cigarette smoking. Tobacco may help them to cope with hunger ${ }^{(63)}$ and the hardships in their lives ${ }^{(64)}$. Time preferences may also intervene in the relationship between FI and smoking behaviour, as present time orientation (giving little thought to the future/living for the time being and not considering the future consequences of current behaviours) is correlated to both cigarette smoking and low socio-economic status $^{(65)}$ and, most likely more drastically, to FI.

The results of previous studies regarding the association between FI and energy intake are somewhat 
contradictory ${ }^{(26,29,66)}$. The present study did not find lower energy intakes among individuals experiencing household FI and suggested a higher frequency of snack eating, as was found in the study by Zizza et al. ${ }^{(66)}$. The energy obtained by snacking may compensate for a reduced meal frequency among FI individuals ${ }^{(66)}$. The present study supports an association between FI and a lower diet quality ${ }^{(24,27,29)}$. In particular, important differences were found regarding the consumption of fruits and vegetables and the consumption of fish. In fact, the FI category was the only category to display a mean consumption of fruits and vegetables $(338 \mathrm{~g} / \mathrm{d})$ clearly lower than the minimum recommended amount of $400 \mathrm{~g} / \mathrm{d}$ and a mean consumption of fish $(164 \mathrm{~g} /$ week $)$ that was also lower than the $200 \mathrm{~g} /$ week recommended by most food-based dietary guidelines ${ }^{(67)}$. On the contrary, the consumption of foods whose intake should be limited such as sweet foods and soft drinks was high (higher than $200 \mathrm{~g} / \mathrm{d}$ ) in both the FI and the FS1 categories. All three diet quality indicators (MAR, MER, ED) also showed that food quality increased from FI to FS4, although absolute differences were rather small. This situation may in part result from financial constraints faced by FI households, as diets composed of low-energy-density nutrient-rich foods (especially fruit, vegetables and fish) are more expensive than diets composed of refined grains, added sugars and added fats ${ }^{(1)}$.

\section{Limitations and strengths}

The findings of the present study should be interpreted with the following methodological limitations in mind. First, FI was assessed using the single-item, four-partresponse Food Sufficiency Indicator of the US Department of Agriculture $^{(4)}$ together with additional questions about the reasons for not having enough food and/or not having the kind of food wanted ${ }^{(43)}$. These questions did not capture the full range of conditions and behaviours associated with FI and hunger, as they are addressed in the more recent and comprehensive instrument, the US Household Food Security Module ${ }^{(4)}$. However, Radimer and Radimer showed that the four-part response to the Food Sufficiency Indicator fairly accurately estimates food insecurity ${ }^{(4)}$. Second, although the participation rate in the survey (63\%) is similar to that obtained in another similar French survey requiring home visits ${ }^{(68)}$, possible occurrence of a selection bias it cannot be excluded. Moreover, the study design excluded some population groups (e.g. non-French speakers, individuals without a residential address) that are most likely poorer than the rest of the population. Weighing data according to French national census data (especially age, sex, occupation of the household head and size of the household) should have limited such bias. Nevertheless, the prevalence of FI in the present study remains most likely slightly underestimated and its results should be extrapolated with caution to the entire adult French population experiencing FI. Third, the cross-sectional nature of the study prevents any causal inference.

Among the strengths of the current study, it is noteworthy that the INCA2 survey included comprehensive factors related to FI, allowing for the first time in France not only an estimation of FI at the national level but also a broad investigation of FI covariates. Finally, underreporting is a common problem in dietary surveys, including the INCA2 survey. As under-reporting has been inversely related to socio-economic status ${ }^{(69,70)}$, associations between FI and dietary intake were assessed after excluding under-reporters. To the best of our knowledge, only one previous study on dietary intakes associated with FI took this phenomenon into account ${ }^{(29)}$.

\section{Conclusions}

Based on a representative sample of the adult population, the present study showed for the first time that France is not immune to FI; approximately one adult out of ten experienced household FI in 2006-2007. Low-income people, single parents (in particular women) and nonhome owners are particularly at risk of FI. Experiencing FI is likely to impinge on the consumption of healthy foods such as fruits and vegetables, thus altering the overall quality of the diet. In addition, people experiencing FI display a less favourable profile with regard to eating between meals, television watching and smoking.

FI is currently not routinely monitored in France. It would be necessary to include the comprehensive instrument, the US Household Food Security Module, in future national surveys to assess trends of FI prevalence in the context of economic crisis, to allow international comparisons and improve our understanding of factors that mitigate vulnerability to FI. Moreover, French authorities should promote research and expert consultations to identify the most effective strategies for reducing problems of FI in the French context. Ensuring financial and geographical accessibility to healthy foods and their attractiveness, especially for people experiencing FI, should be priorities in future national nutrition policies.

\section{Acknowledgements}

Acknowledgements: The authors thank G. Calamassi-Tran, A. Dufour, L. Lafay, M. Touvier and J.-L. Volatier, who contributed to the design and data collection of the INCA2 survey. They also thank the Institut de Sondage Lavialle (ISL) team for the collection of data, and all the families for their cooperation. Financial support: The INCA2 dietary survey was funded by the ANSES (formerly AFSSA). This study was financially supported by the National Observatory on Poverty and Social Exclusion (ONPES). The ONPES had no role in the design, analysis or writing of this article. Conflict of interest: None. Authorship: N.D, 
S.L., C.D. and F.C. contributed to the design of the study. F.V. analysed the data. A.B., F.V. and N.D. conceived the paper and wrote the manuscript. All authors revised and approved the final version of the paper for publication. Etbics of buman subject participation: This survey was approved by the CNIL. Verbal informed consent was obtained from all participants and formally recorded.

\section{References}

1. Darmon N \& Drewnowski A (2008) Does social class predict diet quality? Am J Clin Nutr 87, 1107-1117.

2. Dowler E (2001) Inequalities in diet and physical activity in Europe. Public Health Nutr 4, 701-709.

3. Malon A, Deschamps V, Salanave B et al. (2010) Compliance with French nutrition and health program recommendations is strongly associated with socioeconomic characteristics in the general adult population. $J$ Am Diet Assoc 110, 848-856.

4. Radimer KL \& Radimer KL (2002) Measurement of household food security in the USA and other industrialised countries. Public Health Nutr 5, 859-864.

5. Anderson SA (1990) Core indicators of nutritional state for difficult-to-sample populations. J Nutr 120, Suppl. 11, 1559-1600.

6. Hamelin AM, Beaudry M \& Habicht JP (2002) Characterization of household food insecurity in Quebec: food and feelings. Soc Sci Med 54, 119-132.

7. Food and Agriculture Organization of the United Nations (1996) Rome Declaration on World Food Security and World Food Summit Plan of Action. http://www.fao.org/docrep/ 003/w3613e/w3613e00.HTM (accessed December 2014).

8. Radimer KL, Olson CM, Greene JC et al. (1992) Understanding hunger and developing indicators to assess it in women and children. J Nutr Educ 24, Suppl., 36S-44S.

9. Rose D (1999) Economic determinants and dietary consequences of food insecurity in the United States. J Nutr 129, 2 S Suppl., 517S-520S.

10. Foley W, Ward P, Carter P et al. (2010) An ecological analysis of factors associated with food insecurity in South Australia, 2002-7. Public Health Nutr 13, 215-221.

11. Mello JA, Gans KM, Risica PM et al. (2010) How is food insecurity associated with dietary behaviors? An analysis with low-income, ethnically diverse participants in a nutrition intervention study. J Am Diet Assoc 110, 1906-1911.

12. Ramsey R, Giskes K, Turrell G et al. (2011) Food insecurity among Australian children: potential determinants, health and developmental consequences. J Child Health Care 15, 401-416.

13. Martin-Fernandez J, Grillo F, Parizot I et al. (2013) Prevalence and socioeconomic and geographical inequalities of household food insecurity in the Paris region, France, 2010. BMC Public Health 13, 486.

14. Roustit C, Hamelin AM, Grillo F et al. (2010) Food insecurity: could school food supplementation help break cycles of intergenerational transmission of social inequalities? Pediatrics 126, 1174-1181.

15. Kirkpatrick SI \& Tarasuk V (2011) Housing circumstances are associated with household food access among lowincome urban families. J Urban Health 88, 284-296.

16. Alaimo K, Olson CM \& Frongillo EA Jr (2001) Food insufficiency and American school-aged children's cognitive, academic, and psychosocial development. Pediatrics 108, $44-53$.

17. Alaimo K, Olson CM, Frongillo EA Jr et al. (2001) Food insufficiency, family income, and health in US preschool and school-aged children. Am J Public Health 91, 781-786.
18. Vozoris NT \& Tarasuk VS (2003) Household food insufficiency is associated with poorer health. $J$ Nutr $\mathbf{1 3 3}$, $120-126$.

19. Stuff JE, Casey PH, Szeto KL et al. (2004) Household food insecurity is associated with adult health status. J Nutr 134, 2330-2335.

20. Gucciardi E, Vogt JA, DeMelo M et al. (2009) Exploration of the relationship between household food insecurity and diabetes in Canada. Diabetes Care 32, 2218-2224.

21. Parker ED, Widome R, Nettleton JA et al. (2010) Food security and metabolic syndrome in US adults and adolescents: findings from the National Health and Nutrition Examination Survey, 1999-2006. Ann Epidemiol 20, 364-370

22. Seligman HK, Laraia BA \& Kushel MB (2010) Food insecurity is associated with chronic disease among low-income NHANES participants. J Nutr 140, 304-310.

23. Tarasuk VS \& Beaton GH (1999) Women's dietary intakes in the context of household food insecurity. J Nutr 129, 672-679.

24. Rose D \& Oliveira V (1997) Nutrient intakes of individuals from food-insufficient households in the United States. Am J Public Health 87, 1956-1961.

25. Cristofar SP \& Basiotis PP (1992) Dietary intakes and selected characteristics of women ages 19-50 years and their children ages $1-5$ years by reported perception of food sufficiency. J Nutr Educ 24, 53-58.

26. Kendall A, Olson CM \& Frongillo EA Jr (1996) Relationship of hunger and food insecurity to food availability and consumption. J Am Diet Assoc 96, 1019-1024.

27. Kirkpatrick SI \& Tarasuk V (2008) Food insecurity is associated with nutrient inadequacies among Canadian adults and adolescents. J Nutr 138, 604-612.

28. Bhattacharya J, Currie J \& Haider S (2004) Poverty, food insecurity, and nutritional outcomes in children and adults. $J$ Health Econ 23, 839-862.

29. Dixon LB, Winkleby MA \& Radimer KL (2001) Dietary intakes and serum nutrients differ between adults from food-insufficient and food-sufficient families: Third National Health and Nutrition Examination Survey, 1988-1994. J Nutr 131, 1232-1246.

30. Eicher-Miller HA, Mason AC, Weaver CM et al. (2009) Food insecurity is associated with iron deficiency anemia in US adolescents. Am J Clin Nutr 90, 1358-1371.

31. Kirkpatrick SI \& Tarasuk V (2008) Food insecurity in Canada: considerations for monitoring. Can J Public Health 99, 324-327.

32. Coleman-Jensen A, Nord M, Andrews M et al. (2012) Housebold Food Security in the United States in 2011. Economic Research Report no. ERR-141. Washington, DC: US Department of Agriculture, Economic Research Service.

33. Sarlio-Lahteenkorva S \& Lahelma E (2001) Food insecurity is associated with past and present economic disadvantage and body mass index. J Nutr 131, 2880-2884.

34. Tingay RS, Tan CJ, Tan NC et al. (2003) Food insecurity and low income in an English inner city. J Public Health Med 25, 156-159.

35. Castetbon K, Mejean C, Deschamps V et al. (2011) Dietary behaviour and nutritional status in underprivileged people using food aid (ABENA study, 2004-2005). J Hum Nutr Diet 24, 560-571

36. Dubuisson C, Lioret S, Touvier M et al. (2010) Trends in food and nutritional intakes of French adults from 1999 to 2007: results from the INCA surveys. Br J Nutr 103, $1035-1048$

37. Lioret S, Dubuisson C, Dufour A et al. (2010) Trends in food intake in French children from 1999 to 2007: results from the INCA (etude Individuelle Nationale des Consommations Alimentaires) dietary surveys. Br J Nutr $\mathbf{1 0 3}$ 585-601. 
38. Dufour A, Lafay L \& Volatier JL (2008) La mesure des consommations alimentaires par l'étude INCA2 (The measurement of food consumption by the INCA2 study). In Méthodes de Sondage (Sampling Methods), pp. 132-137 [P Guilbert, D Haziza, A Ruiz-Gazen et al., editors]. Paris: Dunod.

39. Agence Française de Sécurité Sanitaire des Aliments (2009) Etude Individuelle Nationale des Consommations Alimentaires 2 (INCA 2) (2006-2007) - Rapport. MaisonsAlfort: AFSSA.

40. Briefel RR \& Woteki CE (1992) Development of food sufficiency questions for the Third National Health and Nutrition Examination Survey. J Nutr Educ 24, S24-S28.

41. Knol LL, Haughton B \& Fitzhugh EC (2004) Food insufficiency is not related to the overall variety of foods consumed by young children in low-income families. $J \mathrm{Am}$ Diet Assoc 104, 640-644.

42. Townsend MS, Peerson J, Love B et al. (2001) Food insecurity is positively related to overweight in women. J Nutr 131, 1738-1745.

43. Alaimo K, Briefel RR, Frongillo EA Jr et al. (1998) Food insufficiency exists in the United States: results from the third National Health and Nutrition Examination Survey (NHANES III). Am J Public Health 88, 419-426.

44. Lioret S, Touvier M, Lafay L et al. (2008) Are eating occasions and their energy content related to child overweight and socioeconomic status? Obesity (Silver Spring) 16, 2518-2523.

45. National Institute of Statistics and Economic Studies (2014) Definitions and methods. Definitions. Consumption unit. http://www.insee.fr/en/methodes/default.asp?page= definitions/unite-consommation.htm (accessed June 2014).

46. Kendrick T, King F, Albertella L et al. (2005) GP treatment decisions for patients with depression: an observational study. Br J Gen Pract 55, 280-286.

47. Hercberg S, Deheeger M \& Preziosi P (1994) SU-VI-MAX. Portions alimentaires. Manuel photos pour l'estimation des quantites (Portion Sizes: Picture Booklet for the Estimation of Quantities). Paris: Polytechnica.

48. Observatoire de la Composition Nutritionnelle des Aliments (2013) Composition nutritionnelle des aliments TABLE Ciqual (French Food Composition Table - CIQUAL). http:// www.ansespro.fr/TableCIQUAL/ (accessed June 2014).

49. Vieux F, Soler LG, Touazi D et al. (2013) High nutritional quality is not associated with low greenhouse gas emissions in self-selected diets of French adults. Am J Clin Nutr 97, 569-583.

50. Ledikwe JH, Blanck HM, Khan LK et al. (2006) Low-energydensity diets are associated with high diet quality in adults in the United States. I Am Diet Assoc 106, 1172-1180.

51. Schroder H, Vila J, Marrugat J et al. (2008) Low energy density diets are associated with favorable nutrient intake profile and adequacy in free-living elderly men and women. J Nutr 138, 1476-1481.

52. Kantar Worldpanel (2014) French household consumer panel - Kantar worldpanel. http://www.kantarworldpanel. com/global/Sectors/FMCG (accessed June 2014).

53. Cottrell M \& Letrémy P (2007) Missing values: processing with the Kohonen algorithm. ASMDA 2005 CD-ROM Proceedings - ASMDA 2005, Brest, France. http://arxiv.org/ pdf/math/0701152v1.pdf (accessed December 2014).
54. Schofield WN (1985) Predicting basal metabolic rate, new standards and review of previous work. Hum Nutr Clin Nutr 39, Suppl. 1, 5-41.

55. Black AE (2000) Critical evaluation of energy intake using the Goldberg cut-off for energy intake:basal metabolic rate. A practical guide to its calculation, use and limitations. Int J Obes Relat Metab Disord 24, 1119-1130.

56. Coleman-Jensen A, Nord M \& Singh A (2013) Household Food Security in the United States in 2012. Economic Research Report no. ERR-155. Washington, DC: US Department of Agriculture, Economic Research Service.

57. Office of Nutrition Policy and Promotion, Health Canada (2010) Household Food Insecurity in Canada in 2007-08: Key Statistics and Graphics. Ottawa: Health Canada.

58. Auzet L, Février M \& Lapinte A (2007) Niveaux de vie et pauvreté en France: les départements du Nord et du Sud sont les plus touchés par la pauvreté et les inégalités. Insee Première no. 1162 - octobre 2007; available at http://www. insee.fr/fr/themes/document.asp?ref_id=ip1162\&reg_id=0

59. Nord M, Hooper MD \& Hopwood H (2008) Householdlevel income-related food insecurity is less prevalent in Canada than in the United States. J Hunger Environ Nutr 3, $17-35$.

60. Chardon O, Daguet F \& Vivas E (2008) Les familles monoparentales. Des difficultés à travailler et à se loger. Insee Première no. 1195 - juin 2008; available at http://www. insee.fr/fr/themes/document.asp?ref_id=ip1195

61. Cook JT, Black M, Chilton M et al. (2013) Are food insecurity's health impacts underestimated in the U.S. population? Marginal food security also predicts adverse health outcomes in young US children and mothers. Adv Nutr $\mathbf{4}, 51-61$.

62. Armour BS, Pitts MM \& Lee CW (2008) Cigarette smoking and food insecurity among low-income families in the United States, 2001. Am J Health Promot 22, 386-392.

63. Grunberg NE (1986) Nicotine as a psychoactive drug: appetite regulation. Psychopharmacol Bull 22, 875-881.

64. Krueger PM \& Chang VW (2008) Being poor and coping with stress: health behaviors and the risk of death. Am J Public Health 98, 889-896.

65. Peretti-Watel P, L'Haridon O \& Seror V (2013) Time preferences, socioeconomic status and smokers' behaviour, attitudes and risk awareness. Eur J Public Health 23, 783-788.

66. Zizza CA, Duffy PA \& Gerrior SA (2008) Food insecurity is not associated with lower energy intakes. Obesity (Silver Spring) 16, 1908-1913.

67. World Health Organization (2003) Food Based Dietary Guidelines in the WHO European Region. Copenhagen: WHO Regional Office for Europe; available at http://www. euro.who.int/_data/assets/pdf_file/0017/150083/E79832.pdf

68. Castetbon K, Vernay M, Malon A et al. (2009) Dietary intake, physical activity and nutritional status in adults: the French nutrition and health survey (ENNS, 2006-2007). Br J Nutr 102, 733-743.

69. Carter LM \& Whiting SJ (1998) Underreporting of energy intake, socioeconomic status, and expression of nutrient intake. Nutr Rev 56, 179-182

70. Stallone DD, Brunner EJ, Bingham SA et al. (1997) Dietary assessment in Whitehall II: the influence of reporting bias on apparent socioeconomic variation in nutrient intakes. Eur J Clin Nutr 51, 815-825. 